\title{
Flow System with Electrochemical Detection for Determination of Paracetamol in Pharmaceutical Preparations
}

\author{
M.L.S. Silva, ${ }^{a}$ M.B.Q. Garcia,,${ }^{a}{ }^{*}$ J.L.F.C. Lima, ${ }^{a}$ E. Barrado ${ }^{b}$ \\ ${ }^{a}$ REQUIMTE, Departamento de Química-Física, Faculdade de Farmácia da Universidade do \\ Porto, Rua Aníbal Cunha, 164, 4099-030 Porto, Portugal \\ ${ }^{b}$ Departamento de Química Analítica, Facultad de Ciencias de la Universidad de Valladolid, \\ Prado de la Magdalena s/n, 47005 Valladolid, Spain
}

Received 15 November 2005; accepted 5 December 2005

\begin{abstract}
A FIA system with electrochemical detection was developed for the automatic determination of paracetamol in pharmaceutical formulations. The analytical difficulties caused by adsorption of matrix excipients in the electrode surface were surpassed by an on-line electrochemical regeneration of the glassy carbon tubular electrode, using the carrier solution, enabling the renewal of the electrode surface in a simple and rapid way. A single channel FIA manifold was developed, which provided reproducibility of sample transport to the detector and minimized the contact time between samples and electrode surface, thus reducing its cleaning frequency and permitting a high sampling rate to be achieved. Furthermore, the physical characteristics of the electrochemical cell permitted its easy incorporation in the FIA manifold, offering robustness to the system, and allowed it to be generalized to routine analysis applications.

With the optimized parameters, a linear correlation between paracetamol concentration and peak current intensity was obtained up to $4 \times 10^{-4} \mathrm{~mol} \mathrm{~L}^{-1}$, with a detection limit of $2.5 \times 10^{-5} \mathrm{~mol} \mathrm{~L}^{-1}$. Paracetamol was quantified in pharmaceutical dosage forms and the results were compared to those obtained for the official spectrophotometric method (BP 1998). Correlation between the results obtained by both methods was linear and no statistical difference between methods was found at the $95 \%$ confidence level.
\end{abstract}

Keywords: paracetamol, electrochemical detection, tubular electrodes, flow system.

\footnotetext{
* Corresponding author. E-mail address: bquinaz@ff.up.pt
} 


\section{Introduction}

In the recent years, flow injection analysis (FIA) [1] has been frequently applied in the quantification of several compounds present in samples of diverse nature. Implementation of FIA systems in routine analysis offers excellent advantages due to its characteristics. Among them, one can refer the reproducibility of sample processing and transport to the detector, leading to reproducible measurements, the high sampling rates, the simplicity and low cost of the manifolds, the economy in reagent consuming and waste production and the possibility of automation.

Although electrochemical methods exhibit favorable attributes for their use in routine analysis, such as good sensitivity and selectivity, simplicity of design and operation, low cost and relatively short analysis time [2], they haven't been applied so often in the laboratory routine, mainly due to lack of robustness of the detectors and also to electrode surface passivation, that implies recurrent cleaning, unsuitable for routine determinations [3].

Previous work has already demonstrated the advantageous combination of FIA systems with amperometric detection, namely with tubular amperometric detectors, for implementation of automatic standard addition method [4] and multiparametric determinations [5]. The use of a FIA system to transport samples to the detector reduces the contact time between the sample and the electrode, minimizing the adsorption effect. It also enables the continuous flow of the carrier solution between samples, which also favors the electrode cleaning. Additionally, electrochemical pre-treatments of the electrode surface may be performed on-line, without the need to dismount the electrochemical cell. Besides, the physical characteristics of the tubular amperometric detector allow its easy incorporation in the FIA manifold, conferring robustness to the system.

Paracetamol (N-acetyl-p-aminophenol) is a widely available analgesic and antipyretic drug, with weak anti-inflammatory activity. It is given for mild to moderate pain and for fever, and is often the choice for patients in whom NSAIDs are contra-indicated, for children and for elderly patients [6].

Paracetamol can be obtained in a variety of different formulations; therefore, its quantification in these kinds of samples is useful for quality control. Several analytical procedures have been described for paracetamol determination in pharmaceutical preparations, namely spectrophotometric [7-10], electrochemical [11], chemiluminescent [12] and HPLC [13].

The aim of this work was to develop an automatic system based on FIA methodology, in which paracetamol present in pharmaceutical dosage forms could be quantified amperometrically. The proposed method is simple, robust and offers adequate sensitivity for quality control of pharmaceuticals containing paracetamol. 


\section{Experimental}

\section{Reagents and solutions}

Reagents of p.a. or similar quality were used, without further purification. Deionised water with a specific conductance less than $0.1 \mu \mathrm{S} \mathrm{cm} \mathrm{cm}^{-1}$ (Millipore Milli Q) was used throughout.

As supporting electrolyte/carrier solution in the FIA system, the McIlvaine buffer solution ( $\mathrm{pH} 5.5$ ) was used, being prepared by adding $375 \mathrm{~mL}$ of $0.5 \mathrm{~mol} \mathrm{~L}^{-1}$ citric acid (Riedel-de-Haën) to $625 \mathrm{~mL}$ of $1.0 \mathrm{~mol} \mathrm{~L}^{-1}$ di-sodium hydrogen phosphate (Fluka).

Paracetamol (Sigma) standard solutions with concentrations between $5 \times 10^{-5}$ mol L-1 and $4 \times 10^{-4} \mathrm{~mol} \mathrm{~L}^{-1}$ were prepared daily, by dilution of a $1 \times 10^{-2} \mathrm{~mol} \mathrm{~L}^{-1}$ stock solution in the McIlvaine buffer.

Paracetamol was quantified in different dosage forms that are commercially available in Portugal. Twenty tablets were weighed and the average weight was calculated. Afterward, those 20 units were finely powdered and thoroughly mixed. A stock solution of each sample containing $2 \times 10^{-3} \mathrm{~mol} \mathrm{~L}^{-1}$ of paracetamol was prepared by weighting the equivalent sample powder and dissolving it in the McIlvaine buffer. Sample working solutions containing $2 \times$ $10^{-4} \mathrm{~mol} \mathrm{~L}^{-1}$ of paracetamol were obtained by dilution of the respective stock solution in the McIlvaine buffer.

\section{Equipment}

In the developed FIA manifold (Fig. 1), a Gilson Minipuls 3 peristaltic pump equipped with Tygon pumping tubes propelled the solutions. Intercalation of sample and standard segments was made through an injector-commutator of circular movement [14], with functioning characteristics similar to that with horizontal movement previously referred to in the literature [15]. Connection between the different manifold components was made through Omnifit Teflon tubing (0.8 $\mathrm{mm}$ i.d.).

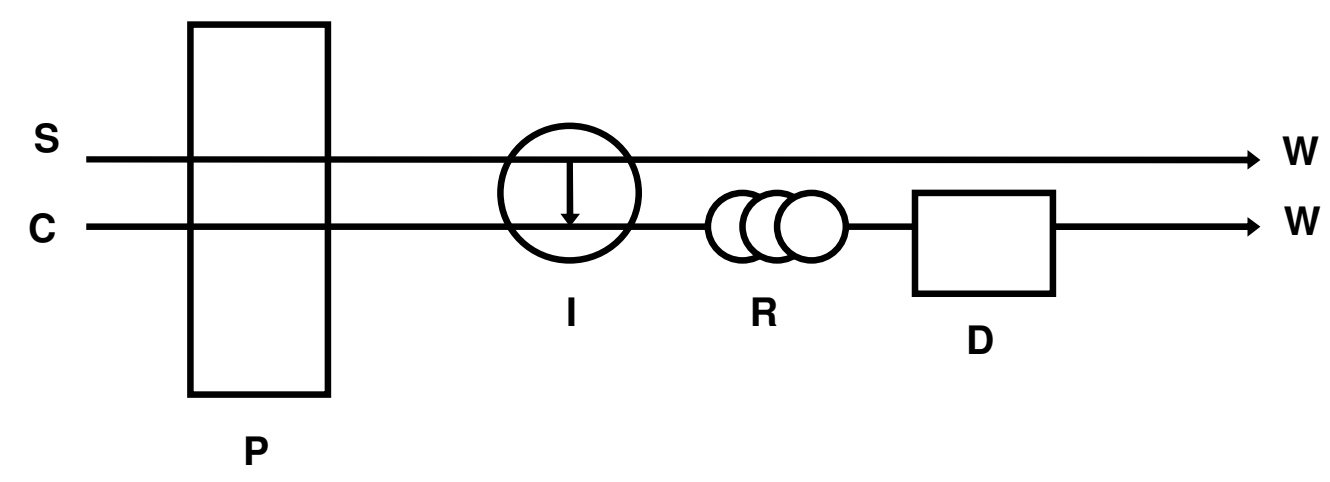

Figure 1. FIA system for paracetamol determination in pharmaceutical preparations. $\mathrm{S}$ - sample or standard solution; $\mathrm{C}$ - carrier solution (Mcllvaine buffer solution, $\mathrm{pH}$ 5.5); $\mathrm{P}$ - peristaltic pump (flow rate $\left.3.4 \mathrm{~mL} \mathrm{~min}^{-1}\right)$; I - injector-commutator $(125 \mu \mathrm{L}) ; \mathrm{R}-$ reactor $(20 \mathrm{~cm})$; D - amperometric detector; $\mathrm{W}$ - waste. 
Amperometric measurements were made in an electrochemical Autolab system (Eco Chemie model PGSTAT 10) and data acquisition was made through GPES software (version 4.6).

\section{Tubular amperometric detector}

The amperometric detector was constructed in a similar way to that recently described in detail [16]. It had a tubular configuration (Fig. 2) and was made up of a central Perspex support, where the working and auxiliary electrodes were housed, strongly fixed to the support by two rubber rings. These two electrodes, both of glassy carbon, were constructed from a $7 \mathrm{~mm}$ diameter glassy carbon rod.

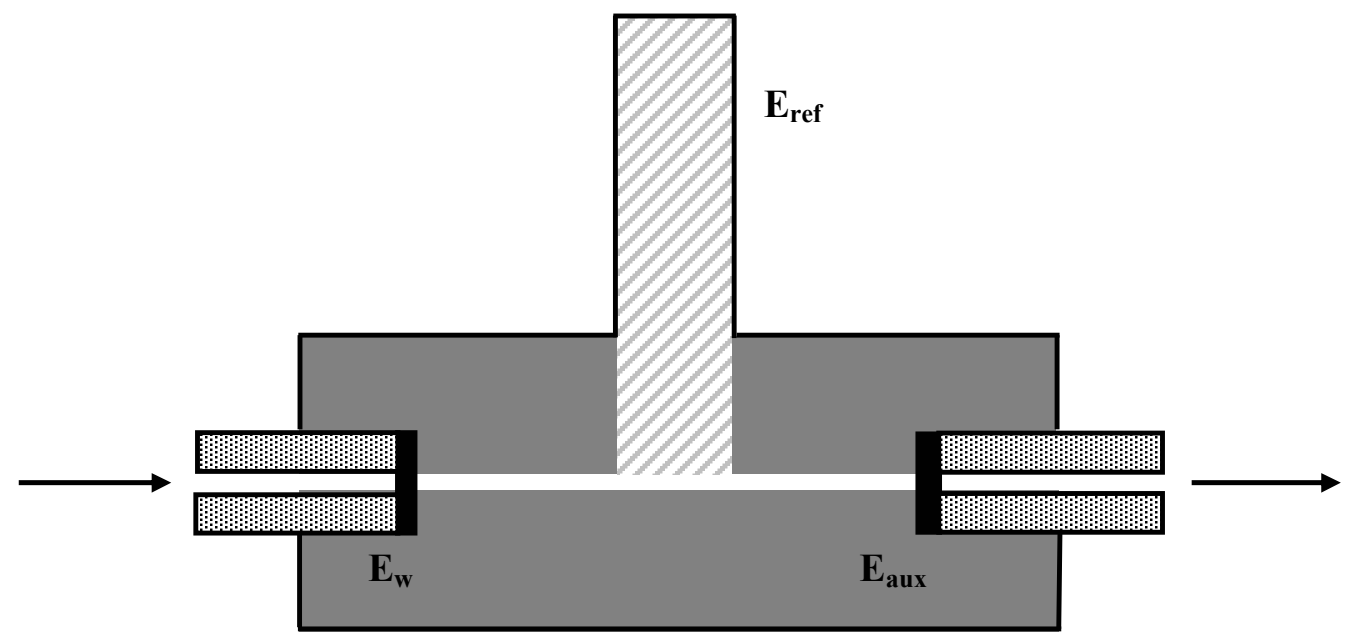

Figure 2. Schematic representation of the electrochemical cell. $E_{\text {ref }}-$ reference electrode; $\mathrm{E}_{\mathrm{w}}$ - working electrode; $\mathrm{E}_{\mathrm{aux}}$ - auxiliary electrode; $\mathrm{a}$ - connection to the manifold; $\rightarrow$ - flow direction.

The resulting cylinders, of $2 \mathrm{~mm}$ thickness, were perforated in the centre creating a $0.8 \mathrm{~mm}$ diameter orifice. As reference electrode, a Metrohm electrode of $\mathrm{Ag} / \mathrm{AgCl}\left(\mathrm{KCl} 3 \mathrm{~mol} \mathrm{~L}^{-1}\right)$ model 6.0727.000 was used, fixed by a threaded screw and superficially touching the central channel which linked the working electrode to the auxiliary electrode, where the solutions flowed. The electrical contact with the working and auxiliary electrodes was established through two metallic screws fitted into the Perspex support.

\section{Results and discussion}

\section{Electrochemical behaviour of paracetamol}

The electro-oxidation of paracetamol was studied by cyclic voltammetry (Fig. 3), using the tubular detector incorporated in the FIA manifold, with a paracetamol standard solution $\left(1 \times 10^{-4} \mathrm{~mol} \mathrm{~L}^{-1}\right)$ flowing continuously in the system, at a 0.5

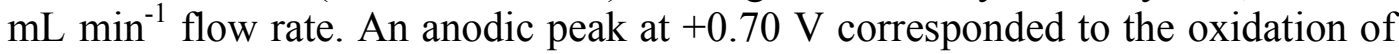
paracetamol (Fig. 4-I), generating N-acetyl-p-quinoneimine (NAPQI, Fig. 4-II), in a $\mathrm{pH}$-dependent two-electron process [17], while a much smaller cathodic 
peak at $+0.10 \mathrm{~V}$ was observed on the reverse scan. All subsequent reactions (Fig. 4) are nonelectrochemical but also $\mathrm{pH}$-dependent.

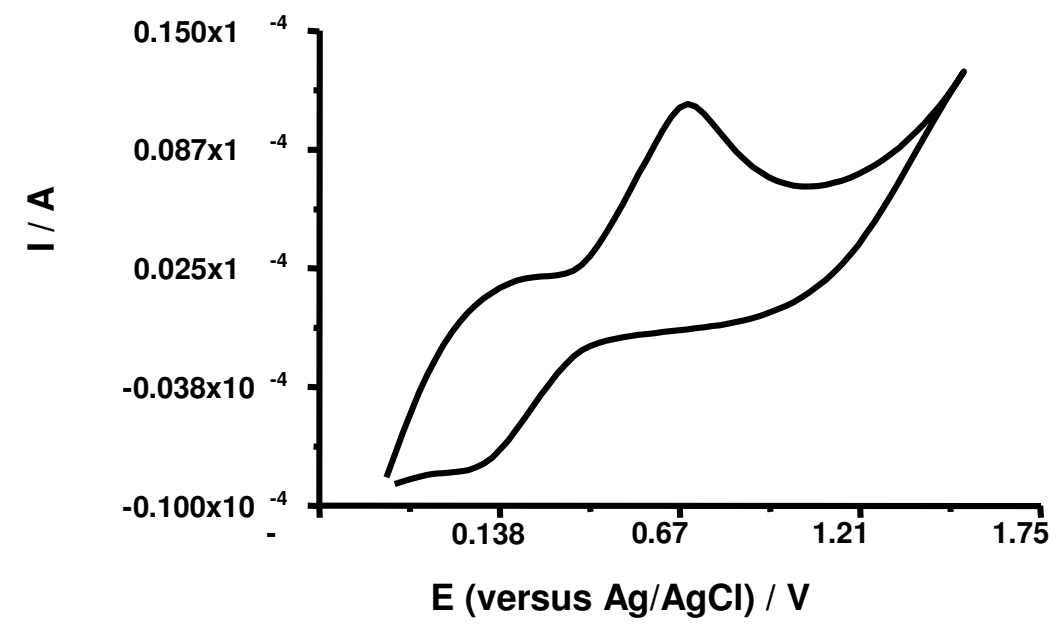

Figure 3. Cyclic voltamogram obtained for a paracetamol standard solution $1 \times 10^{-4}$ mol L ${ }^{-1}$ in McIlvaine buffer solution ( $\mathrm{pH} 5.5$ ); flow rate $0.5 \mathrm{~mol} \mathrm{~L}^{-1}$; scan rate $0.2 \mathrm{~V} \mathrm{~s}^{-1}$.

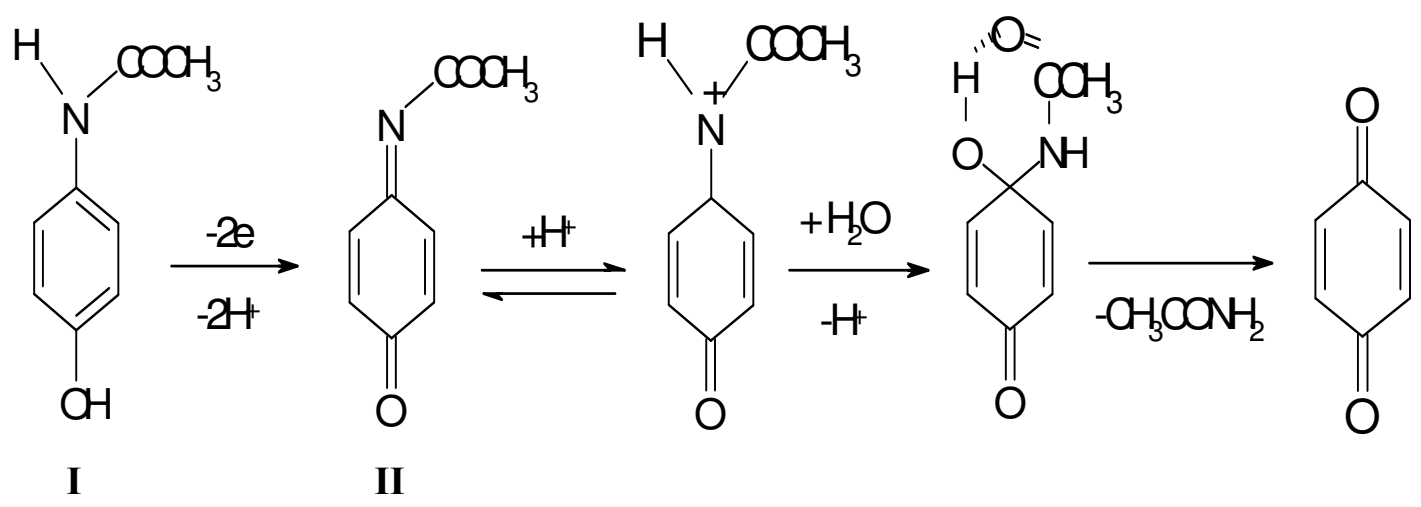

Figure 4. Electrochemical oxidation of paracetamol and subsequent chemical reactions. I - paracetamol; II - N-acetyl-p-quinoneimine (NAPQI).

Performing the cyclic voltammetry at different scan rates, a linear correlation between the square root of scan rate from 10 to $200 \mathrm{mV} \mathrm{s}^{-1}$ and peak current intensity $\left(I_{p}\right)$ was observed $\left(R^{2}=0.992\right)$, suggesting a typical diffusion-controlled electrochemical process.

\section{pH of supporting electrolyte/carrier solution}

The effect of $\mathrm{pH}$ on $\mathrm{I}_{\mathrm{p}}$ was examined, varying the $\mathrm{pH}$ of the supporting electrolyte/carrier solution (McIlvaine buffer solution $0.5 / 1.0 \mathrm{~mol} \mathrm{~L}{ }^{-1}$ ) from 2 to 8 , and measuring the $\mathrm{I}_{\mathrm{p}}$ obtained for a paracetamol standard solution $1 \times 10^{-4}$ mol $\mathrm{L}^{-1}$. The $\mathrm{I}_{\mathrm{p}}$ increased until 5.5 and then it decreased (Fig. 5); hence this $\mathrm{pH}$ value was used for all the subsequent measurements. 


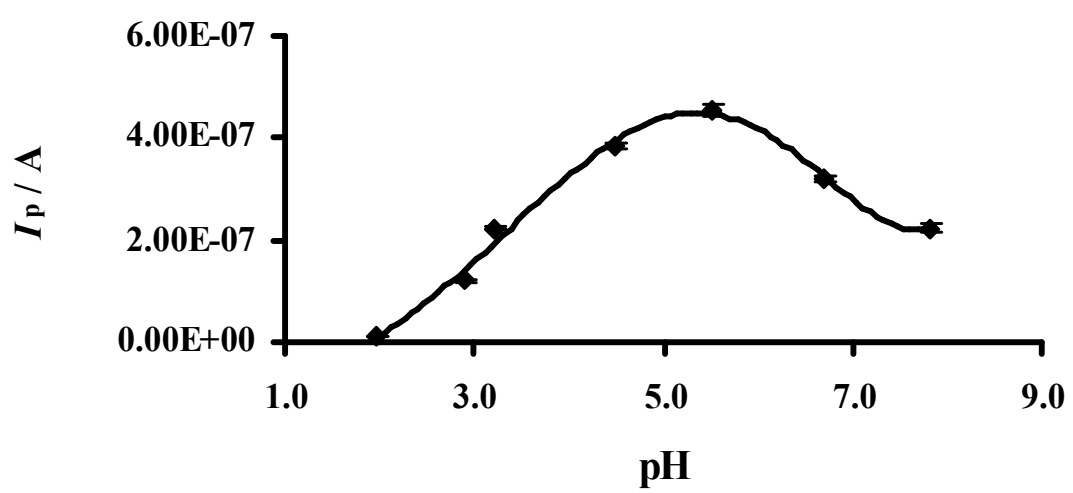

Figure 5. Effect of $\mathrm{pH}$ on peak current intensity $\left(\mathrm{I}_{\mathrm{p}}\right)$ for a $1 \times 10^{-4} \mathrm{~mol} \mathrm{~L}^{-1}$ paracetamol standard solution in $0.5 / 1.0 \mathrm{~mol} \mathrm{~L}^{-1}$ McIlvaine buffer. Potential $0.60 \mathrm{~V}$; flow rate 1.7 $\mathrm{mL} \min ^{-1}$; sample injection volume $100 \mu \mathrm{L}$.

\section{Chemical and electrochemical regeneration of the electrode}

The working electrode surface was electrochemically regenerated on-line with the carrier solution flowing through the detector, by potential cycling between $0.2 \mathrm{~V}$ and $2.0 \mathrm{~V}$ for two cycles, with a step potential of $0.02 \mathrm{~V}$ and a scan rate of $0.20 \mathrm{~V} \mathrm{~s}^{-1}$. Since the aim of this work was to develop an automatic system which allowed continuous sample analyses, the number of determinations which could be undertaken successively, after an electrochemical cleaning step and maintaining the same $I_{\mathrm{p}}$, was evaluated. Repeated measurements of a $1 \times 10^{-4}$ mol L $\mathrm{L}^{-1}$ paracetamol standard solution were carried out, and the results showed that $I_{\mathrm{p}}$ remained with the same value for 50 determinations, beginning to decline for subsequent measurements. This way, the electrochemical treatment needed to be repeated after every 50 determinations, which only took approximately 1 minute. The electrochemical surface regeneration was performed on-line, without the need to dismount the electrochemical cell and using the carrier solution, thus the sampling rate was not affected by the changing of solutions that this regeneration step could imply. Therefore, the FIA manifold kept its simple design.

\section{Optimization of the manifold parameters}

The system parameters were optimized by using the factorial design at 2 levels, because it allows the measurement of effects of factors and their interactions, and a maximum amount of information can be obtained with a minimum of runs. The system parameters were optimized in order to obtain the higher $I_{\mathrm{p}}$. Four controllable factors that could affect the $I_{\mathrm{p}}$ were identified: applied potential (E), flow rate (FR), sample injection volume (V) and reactor length (R). A fractional factorial design $2^{4-1}$ (4 factors and 2 levels) was used to screen the factors that influenced most significantly the response. The levels of the factors are indicated in Table 1, and were chosen according to previous studies performed by the 
univariate method, which allowed to verify the effect of flow system parameters in the $I_{p}$.

Table 1. Controllable factors and correspondent low (-) and high (+) levels chosen for the factorial design.

\begin{tabular}{|c|c|c|}
\hline \multirow{2}{*}{ Factors } & \multicolumn{2}{|c|}{ Levels } \\
\cline { 2 - 3 } & - & + \\
\hline Applied potential (E) / V & 0.60 & 1.10 \\
\hline Flow rate (FR) / mL min-1 & 1.7 & 3.4 \\
\hline Sample injection volume (V) $/ \mu \mathrm{L}$ & 40 & 120 \\
\hline Reactor length (R) / cm & 10 & 50 \\
\hline
\end{tabular}

Regarding the applied potential, an increase in the potential from $0.60 \mathrm{~V}$ to about $1.00 \mathrm{~V}$ would result in an increase of $I_{p}$, beyond which no further increase was expected, thus the lower and higher levels were selected being $0.60 \mathrm{~V}$ and 1.00 $\mathrm{V}$, respectively.

The variation of flow rate influenced also the $I_{p}$, with higher flow rate values originating a higher response, enabling also a higher sampling rate. Though, with high flow rate values (beyond $3.5 \mathrm{~mL} \mathrm{~min}^{-1}$ ), an increase of irreproducibility of $I_{p}$ was observed, so the optimization experiments were carried out with flow rate values between 1.7 and $3.4 \mathrm{~mL} \mathrm{~min}^{-1}$.

As for the sample injection volume, values lower than $40 \mu \mathrm{L}$ would result in more irreproducible $I_{p}$, owing to mechanical limitations of the injectorcommutator, and for values higher than $120 \mu \mathrm{L}$, though a higher $I_{p}$ was expected, a decrease in the sampling rate would also occur, thus the lower and higher levels chosen for sample injection volume were 40 and $120 \mu \mathrm{L}$, correspondingly.

Concerning the reactor length between the injection site and the detector, since it wasn't necessary to increase the dispersion of samples, the lower and higher levels chosen were 10 and $50 \mathrm{~cm}$, respectively. Reactor lengths higher than 50 $\mathrm{cm}$ would result in lower sampling rates.

Runs were carried out in duplicate and in a random way to minimize the effects of uncontrollable factors. A $1 \times 10^{-4} \mathrm{~mol} \mathrm{~L}^{-1}$ paracetamol standard solution was used throughout.

Using the Yates algorithm, it was found that all the factors influenced the response since in all cases the experimental $F$ value $\left(\mathrm{F}_{\text {exp }}\right)$, of the $F$ test, was higher than the critical $F$ value $\left(F_{\text {crit }}\right)$, with an influence order of $V>R>F R>E$. A complete factorial design with the first 3 factors and 2 levels was carried out to confirm these results, and E was set in $1.10 \mathrm{~V}$, which originated a higher $I_{\mathrm{p}}$ in the fractional factorial design.

For the complete factorial design the previous low and high levels of the controllable factors were used. Again, runs were carried out in duplicate and in a random way, and a $1 \times 10^{-4} \mathrm{~mol} \mathrm{~L}^{-1}$ paracetamol standard solution was used. The results of the complete factorial design (Table 2) confirmed the influence of the 
tested factors and their interactions in the response. As expected, a higher $I_{\mathrm{p}}$ was obtained when FR and V were in the high level and R was in the low level.

Table 2. Complete factorial design matrix and results.

\begin{tabular}{|c|c|c|c|c|c|c|c|c|c|c|}
\hline \multicolumn{7}{|c|}{ Factors levels } & \multirow{2}{*}{$\begin{array}{c}I_{\mathrm{p}}{ } \times 10^{-7} \mathrm{~A} \\
(\mathrm{n}=2)\end{array}$} & \multirow{2}{*}{ Factor } & \multirow{2}{*}{$F_{\text {exp }}$} & \multirow{2}{*}{$\mathrm{F}_{\text {crit }}$} \\
\hline FR & $\mathrm{V}$ & $\mathrm{R}$ & $\mathrm{FR} \times \mathrm{V}$ & $\mathrm{FR} \times \mathrm{R}$ & $\mathrm{V} \times \mathrm{R}$ & $\mathrm{FR} \times \mathrm{V} \times \mathrm{R}$ & & & & \\
\hline- & - & - & + & + & + & - & 5.468 & FR & 93.355 & 7.571 \\
\hline+ & - & - & - & - & + & + & 5.691 & $\mathrm{~V}$ & 572.441 & \\
\hline- & + & - & - & + & - & + & 9.036 & $\mathrm{R}$ & 143.412 & \\
\hline- & - & + & + & - & - & + & 2.510 & $\mathrm{FR} \times \mathrm{V}$ & 53.774 & \\
\hline- & + & + & - & - & + & - & 5.363 & $\mathrm{FR} \times \mathrm{R}$ & 26.624 & \\
\hline+ & - & + & - & + & - & - & 5.318 & $\mathrm{~V} \times \mathrm{R}$ & 11.342 & \\
\hline+ & + & - & + & - & - & - & 12.685 & $\mathrm{FR} \times \mathrm{V} \times \mathrm{R}$ & 2.319 & \\
\hline+ & + & + & + & + & + & + & 10.420 & & & \\
\hline
\end{tabular}

$\mathrm{V}$ and $\mathrm{R}$ were the factors that influenced most significantly the $I_{\mathrm{p}}$ so they were optimized by using the modified simplex method [18], and FR was kept at 3.4 $\mathrm{mL} \min ^{-1}$ (which generated a higher $I_{\mathrm{p}}$ ). Fig. 6 shows the optimization sequence obtained with the modified simplex method. The simplex optimization led to the optimum values of sample injection volume of $125 \mu \mathrm{L}$ and reactor length of 20 $\mathrm{cm}$.

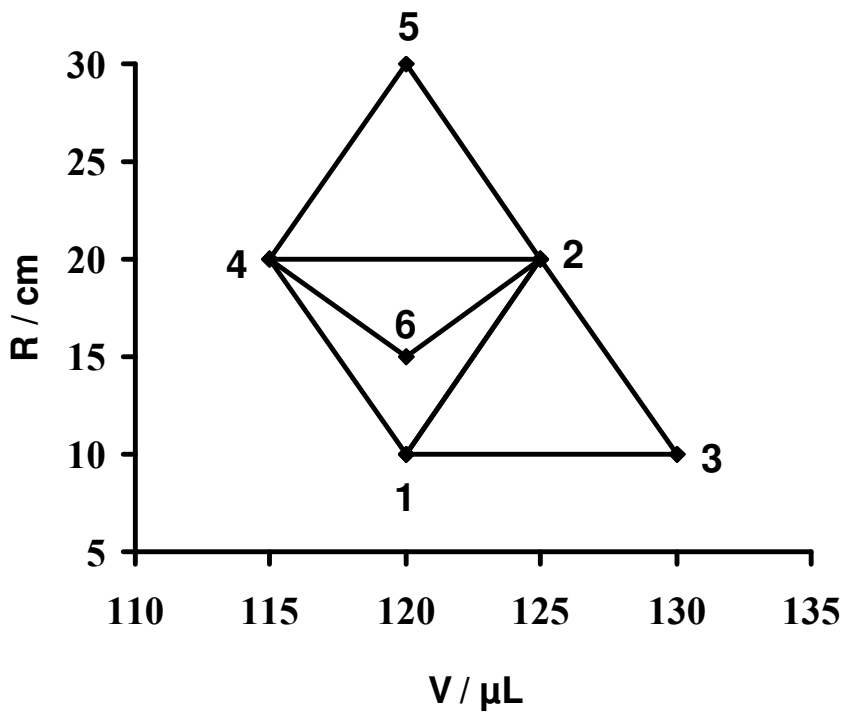

Figure 6. The optimization sequence obtained with the modified simplex method for sample injection volume and reactor length. Paracetamol standard solution $1 \times 10^{-4} \mathrm{~mol}$ $\mathrm{L}^{-1}$; potential $1.10 \mathrm{~V}$; flow rate $3.4 \mathrm{~mL} \mathrm{~min}^{-1}$.

Using the optimized parameters, a linear correlation between paracetamol concentration and $I_{\mathrm{p}}$ up to $4 \times 10^{-4} \mathrm{~mol} \mathrm{~L}^{-1}$ was obtained, with a detection limit of $2.4 \times 10^{-5} \mathrm{~mol} \mathrm{~L}^{-1}$, calculated from the regression equation [19]. The sampling rate was calculated considering the time needed to perform the regeneration step 
and the following 50 determinations, therefore the system enabled a sampling rate of 50 determinations in about 40 minutes. Repeatability assays were carried out for all the standard solutions and the relative standard deviation (RSD) of $I_{\mathrm{p}}$ was always lower than $5 \%(n=9)$

\section{Interference studies}

Excipients that were present in the samples to be analyzed (sorbitol, sodium benzoate, citric acid and sodium bicarbonate) were tested to check their interference in paracetamol quantification. Several standard solutions containing $1 \times 10^{-4} \mathrm{~mol} \mathrm{~L}^{-1}$ paracetamol and different excipient concentrations were analyzed and the $I_{\mathrm{p}}$ was compared to that obtained for a $1 \times 10^{-4} \mathrm{~mol} \mathrm{~L}^{-1}$ paracetamol standard solution. An excipient concentration was considered to interfere in paracetamol determination if it caused a variation in $I_{\mathrm{p}} \geq 3 \%$, compared to $I_{\mathrm{p}}$ of the paracetamol standard solution in the absence of any excipient. It was found that sorbitol and sodium bicarbonate didn't interfere for a concentration 100-fold higher than that of paracetamol, and sodium benzoate and citric acid didn't interfere for a concentration 40-fold and 20-fold higher, respectively. Considering the excipients concentration in the samples, which are in a lower proportion than those tested, it was concluded that these excipients didn't interfere in paracetamol quantification in pharmaceutical formulations.

\section{Analytical application to pharmaceutical formulations}

In order to assess the usefulness of the developed method, it was applied to the determination of paracetamol in seven pharmaceutical dosage forms available in Portugal.

The FIA system was calibrated in the concentration range up to $4 \times 10^{-4} \mathrm{~mol} \mathrm{~L}^{-1}$ and the samples were analyzed. In order to evaluate the accuracy of the results obtained by the proposed method, samples were also analyzed by the official spectrophotometric method (BP 1998) [20]. Absorbance measurements were carried out in a UV/VIS spectrometer (PerkinElmer Instruments). The results are indicated in Table 3.

Correlation between the results obtained by both methods was linear $\left(\mathrm{R}^{2}=0.999\right.$, $\mathrm{a}=18.16 \pm 26.48, \mathrm{~b}=0.96 \pm 0.04$, random residuals). Agreement between the results was also evaluated by the $t$-test for paired data, and there was no statistical difference between the results from both methods $\left(\mathrm{t}_{\text {calc }}=-0.88<\mathrm{t}_{\text {crit }}=2.45, \mathrm{n}_{1}=\right.$ $\mathrm{n}_{2}=7$ and $\mathrm{P}=0.05$ ). To assess the repeatability of results, successive injections of all samples were carried out, and RSD of concentration was always $<5 \%$ $(n=9)$. 
Table 3. Results obtained in the analysis of pharmaceuticals by the proposed method and the reference method.

\begin{tabular}{|c|c|c|c|c|}
\hline \multirow{2}{*}{$\begin{array}{l}\text { Pharmaceutical } \\
\text { formulation }\end{array}$} & \multirow{2}{*}{$\begin{array}{l}\text { Label amount / (mg } \\
\left.\text { unit }^{-1}\right)\end{array}$} & \multicolumn{2}{|c|}{ Content found / $\left(\mathrm{mg} \mathrm{unit}^{-1}\right)$} & \multirow{2}{*}{$\begin{array}{c}\text { Relative } \\
\text { deviation / \% }\end{array}$} \\
\hline & & $\begin{array}{l}\text { Proposed } \\
\text { method }^{\text {a }}\end{array}$ & $\begin{array}{l}\text { Reference } \\
\text { method }^{\text {a }}\end{array}$ & \\
\hline $\begin{array}{l}\text { Ben-u-ron }{ }^{\circledR}, \\
\text { tablets }\end{array}$ & 500 & $497.2 \pm 4.7$ & $495.6 \pm 3.4$ & +0.3 \\
\hline $\begin{array}{l}\text { Panadol }{ }^{\circledR}, \\
\text { tablets }\end{array}$ & 500 & $499.6 \pm 12.4$ & $494.6 \pm 1.6$ & +1.0 \\
\hline $\begin{array}{c}\text { Panasorbe } \AA, \\
\text { tablets }\end{array}$ & 500 & $486.2 \pm 14.4$ & $499.1 \pm 3.1$ & -2.6 \\
\hline $\begin{array}{l}\text { Tylenol }{ }^{\circledR}, \\
\text { tablets }\end{array}$ & 500 & $495.9 \pm 13.3$ & $488.3 \pm 4.9$ & +1.6 \\
\hline $\begin{array}{c}\text { Farmasan }{ }^{\circledR}, \\
\text { tablets }\end{array}$ & 500 & $484.0 \pm 4.6$ & $492.8 \pm 0.6$ & -1.8 \\
\hline $\begin{array}{l}\text { Dafalgan } \AA, \\
\text { effervescent } \\
\text { tablets }\end{array}$ & 1000 & $979.2 \pm 7.0$ & $999.0 \pm 6.1$ & -2.0 \\
\hline $\begin{array}{c}\text { Efferalgan } \AA, \\
\text { effervescent } \\
\text { tablets }\end{array}$ & 500 & $498.9 \pm 4.3$ & $495.8 \pm 5.1$ & +0.6 \\
\hline
\end{tabular}

${ }^{a}$ Average and standard deviation of 3 independent determinations of each sample.

\section{Conclusions}

The developed automatic procedure has proved to be a good alternative for paracetamol determination in quality control of pharmaceutical preparations. It yields results similar to those furnished by the reference spectrophotometric method and shows good sensitivity and sampling rate.

The use of a continuous flow system minimized the contact time between the sample and the detector which, together with the flowing of the carrier solution between samples, decreased the electrode fouling, due to the adsorption of matrix excipients. This enabled a reduction in the frequency of electrode regeneration. Furthermore, the method is simple, easy to operate, inexpensive and allows a high sampling rate, suitable for routine analysis. Additionally, sample pretreatment steps were reduced and the consumption of reagents was minimized, comparing with the reference method. The robustness exhibited by the tubular amperometric detector and the ease of incorporation in the flow system enables its application in regular laboratory use. Moreover, the developed flow system with electrochemical detection could be easily applied to the quality control analysis of other drugs in pharmaceutical products or in dissolution assays. 


\section{Acknowledgements}

The authors are grateful to the Portuguese-Spanish investigators exchange (Acção Integrada E-41/03, HP2002-0039). M. L. S. Silva thanks FCT and FSE (III Quadro Comunitário de Apoio) for a Ph. D. grant (BD/10385/02).

\section{References}

1. J. Ružička, E.H. Hansen, Anal. Chim. Acta 78 (1975) 145-157.

2. K. Tóth, K. Štulík, W. Kutner, Z. Fehér, E. Lindner, Pure Appl. Chem. 76 (2004) 1119-1138.

3. K. Štulík, Electroanalysis 11 (1999) 1001-1004.

4. R.I.L. Catarino, M.B. Garcia, J.L.F.C. Lima, E. Barrado, M. Vega, Electroanalysis 14 (2002) 741-746.

5. R.I.L. Catarino, M.B. Garcia, R.A.S. Lapa, J.L.F.C. Lima, E. Barrado, J. AOAC Int. 85 (2002) 1253-1259.

6. Martindale, The Complete Drug Reference, S.C. Sweetman, Ed., $33^{\text {rd }}$ edition, Pharmaceutical Press, London, 2002, p.71-74.

7. Z. Bouhsain, S. Garrigues, A. Morales-Rubio, M. Guardia, Anal. Chim. Acta 330 (1996) 59-69.

8. M.L. Ramos, J.F. Tyson, D.J. Curran, Anal. Chim. Acta 364 (1998) 107116.

9. $\quad$ J.K.F. Staden, M.M. Tsanwani, Talanta 58 (2002) 1095-1101.

10. M. Knochen, J. Giglio, B.F. Reis, J. Pharm. Biomed. Anal. 33 (2003) 191197.

11. O. Fatibello-Filho, K.O. Lupetti, I.C. Vieira, Talanta 55 (2001) 685-692.

12. D. Easwaramoorthy, Y. Yu, H. Huang, Anal. Chim. Acta 439 (2001) 95100.

13. L. Monser, F. Darghouth, J. Pharm. Biomed. Anal. 27 (2002) 851-860.

14. E.A.G. Zagatto, H. Bergamin, S.M.B. Brienza, M.A.Z. Arruda, A.R.A. Nogueira, J.L.F.C. Lima, Anal. Chim. Acta 261 (1992) 59-65.

15. F.J. Krug, H. Bergamin, E.A.G. Zagatto, Anal. Chim. Acta 179 (1986) 103118.

16. R.I.L. Catarino, A.C.L. Conceição, M.B. Garcia, M.L.S. Gonçalves, J.L.F.C. Lima, M.M.C. Santos, J. Pharm. Biom. Anal. 33 (2003) 571-580.

17. D.J. Miner, J.R. Rice, R.M. Riggin, P.T. Kissinger, Anal. Chem. 53 (1981) 2258-2263.

18. J.A. Nelder, R. Mead, Comp. J. 7 (1965) 308-313.

19. J.N. Miller, J.C. Miller, in Statistics and Chemometrics for Analytical Chemistry, $4^{\text {th }}$ edition, Pearson Education Limited, Harlow, 2000, p.120123.

20. The British Pharmacopoeia 1998, HM Stationery Office, Vol. II, London, p. 1854-1856. 